\title{
Relationship Between Glycine Transporter I Inhibition as Measured with Positron Emission Tomography and Changes in Cognitive Performances in Nonhuman Primates
}

\author{
SA Castner', NV Murthy ${ }^{2}$, K Ridler $^{3}$, H Herdon ${ }^{2}$, BM Roberts', DP Weinzimmer ${ }^{4}$, Y Huang $^{4}$, MQ Zheng $^{4}$, \\ EA Rabiner ${ }^{3}$, RN Gunn ${ }^{3}$, RE Carson ${ }^{4}$, GV Williams' and M Laruelle*, ${ }^{*, 1,2,4,5}$ \\ 'Department of Psychiatry, Yale University School of Medicine, New Haven, CT, USA; ${ }^{2}$ Neurosciences Centre for Excellence in Drug Discovery, \\ GlaxoSmithKline, Harlow, UK; ${ }^{3}$ Clinical Imaging Centre, GlaxoSmithKline, Hammersmith Hospital-Imperial College, London, UK; ${ }^{4}$ Department of \\ Radiology, Yale University School of Medicine, New Haven, CT, USA; ${ }^{5}$ UCB Pharma, Braine-l'Alleud, Brussels, Belgium
}

\begin{abstract}
Several lines of evidence suggest that schizophrenia is associated with deficits in glutamatergic transmission at the N-methyl-D-aspartate (NMDA) receptors. Glycine is a NMDA receptor co-agonist, and extracellular levels of glycine are regulated in the forebrain by the glycine type-I transporters (GlyT-I). GlyT-I inhibitors elevate extracellular glycine and thus potentiate NMDA transmission. This mechanism represents a promising new avenue for the treatment of schizophrenia. Here, the recently introduced positron emission tomography radiotracer [ I C]GSK93 | I 45 was used to quantify the relationship between occupancy of GlyT- I by a GlyT- I inhibitor, Org 25935, and its impact on spatial working memory performances in rhesus monkeys. The effect of Org 25935 on working memory was assessed both in control conditions and during a state of relative NMDA hypofunction induced by ketamine administration, at a dose selected for each animal to reduce task performance by about 50\%. Under control conditions, Org 25935 had no effect on working memory at GlyT-I occupancies lower than 75\% and significantly impaired working memory at occupancies higher than 75\%. Under ketamine conditions, Org 25935 reversed the deficit in working memory induced by ketamine and did so optimally in the 40-70\% GlyT- I occupancy range. The results confirm the efficacy of this mechanism to correct working memory deficits associated with NMDA hypofunction. These data also suggest the existence of an inverted- $U$ dose-response curve in the potential therapeutic effect of this class of compounds.

Neuropsychopharmacology (20I4) 39, 2742-2749; doi:I0.I038/npp.20I4.4; published online 6 August 20I4
\end{abstract}

Keywords: schizophrenia; glutamate; glycine transporter inhibitor

\section{INTRODUCTION}

Alterations in glutamate $N$-methyl-D-aspartate (NMDA) transmission are postulated to be involved in the pathophysiology of schizophrenia (for reviews see Coyle, 2004; Hui et al, 2009, Javitt, 2009; Lisman et al, 2008; Moghaddam and Javitt, 2012). This proposition essentially stems from the observation that, in humans, exposure to subanesthetic doses of NMDA receptors antagonists such as ketamine or phencyclidine induces symptoms reminiscent of those presented by patients with schizophrenia, including psychotic symptoms, negative symptoms, and cognitive dysfunction (Chen and Weston, 1960; Javitt and Zukin, 1991; Kantrowitz and Javitt, 2010; Krystal et al, 1994; Luby et al, 1962). Although direct and unambiguous evidence of NMDA receptor dysfunction in schizophrenia is still

* Correspondence: Professor M Laruelle, UCB Pharma, Chemin du Foriest, Braine-l'Alleud 1420, Belgium, Tel: + I 914316 0923, Fax: + 322386 2550, E-mail: ml393@columbia.edu

Received 27 February 2012; revised 4 November 2013; accepted 13 December 2013; accepted article preview online 3 February 2014 lacking, these observations suggest that enhancing NMDA transmission might be beneficial for patients with schizophrenia (Marek et al, 2010; Moghaddam and Javitt, 2012).

The endogenous amino-acid glycine and its precursor D-serine are co-agonists at the NMDA receptors (Dingledine et al, 1990; Thomson, 1990). Some, but not all, clinical studies on glycine and D-serine augmentation of antipsychotic treatment in schizophrenia reported clinical benefits, mainly in terms of alleviation of negative symptoms (reviews and meta-analyses in Javitt, 2008; Singh and Singh, 2011; Tsai and Lin, 2010). Yet, the magnitude of extracellular glycine increase achieved in the vicinity of the NMDA receptors by these oral regimen remains to be clarified. An alternative and presumably more effective method to raise glycine levels at the NMDA receptor sites is blockage of the glycine transporter (Gly-T) (Javitt, 2009).

Glycine extracellular levels are controlled by GlyT-1 and GlyT-2 (Bergeron et al, 1998; Borowsky et al, 1993; Liu et al, 1993; Smith et al, 1992). GlyT-1 shows a widespread distribution in the brain and is expressed on glial cells as well as on neuronal pre- and post-synaptic sites of NMDA synapses. In contrast, GlyT-2 is found mostly in the spinal 
cord and brainstem and appears to be involved in the regulation of glycine at the inhibitory glycine receptors. Thus, GlyT-1 is the target of choice for raising glycine concentration in the forebrain. Small studies with augmentation of antipsychotic treatment using the naturally occurring GlyT-1 inhibitor sarcosine have reported positive results in schizophrenic patients (Singh and Singh, 2011; Tsai and Lin, 2010). Hence, several efforts are underway to develop high-affinity GlyT-1 inhibitors as novel medications for treating schizophrenia (Hashimoto, 2011; Lechner, 2006; Wallace et al, 2011; Wolkenberg and Sur, 2010).

GlyT-1 inhibitors are effective in most rodent models of schizophrenia associated with alterations in NMDA transmission (Alberati et al, 2011; Boulay et al, 2010; Yang et al, 2010). GlyT-1 inhibitors have also been reported to alleviate some of the ketamine-induced behavioural and cognitive disturbances in nonhuman primates (Roberts et al, 2010b) and in humans (D'Souza et al, 2011). The GlyT-1 inhibitor bitopertin (RG1678) was recently shown to improve negative symptoms when administered as augmentation to antipsychotic drugs in a proof-of-concept phase 2 study in stable patients with schizophrenia (Umbricht et al, 2014).

[11C]GSK931145 is a newly developed positron emission tomography (PET) radioligand suitable for quantifying GlyT1 availability in the living brain (Gunn et al, 2011; Passchier et al, 2010). [11C]GSK931145 was successfully used to measure the occupancy of GlyT-1 achieved by the GlyT-1 inhibitor GSK1018921 in healthy humans (Gunn et al, 2011). Other PET imaging ligands for GlyT-1 have been recently reported, such as [11C]R05013853 (Borroni et al, 2013; Wong et al, 2011) and [18F]MK-6577 (Hamill et al, 2011; SanabriaBohorquez et al, 2011). The availability of these ligands enables precise selection of the doses of GlyT-1 inhibitors to be used in clinical trials, based on the desired level of GlyT-1 occupancy. However, the optimal level of GlyT-1 occupancy by inhibitors associated with cognitive and clinical benefits in schizophrenia remains to be fully characterized.

The aim of the present study was to characterize the relationship of GlyT-1 occupancy by the GlyT-1 competitive inhibitor Org 25935 with cognitive effects in rhesus monkeys. Org 25935 is a sarcosine analog GlyT-1 competitive inhibitor (Zhang et al, 2011) that has been shown to reverse phencyclidine-induced cognitive deficit in a rat novel object recognition test at low but not high doses (Nations et al, 2012). First, the dose-occupancy relationship of Org 25935 was characterised in the rhesus brain using PET with [11C]GSK931145. Second, the effect of various doses of Org 25935 was assessed on a working memory task (spatial delayed response task) under baseline conditions and following pretreatment with ketamine. Under control conditions, the task difficulty was calibrated for each animal to a correct response rate of $\pm 70 \%$, enabling detection of both improvement and decrement in performance following drug administration. The ketamine dose was selected for each animal in order to induce a $50 \%$ decrement in cognitive performance compared with baseline.

\section{MATERIALS AND METHODS}

Eleven middle-aged adult (14-20 years old) rhesus macaques (Macaca mulatta, five male and six females) were involved in this study. The animal care and use was in accordance with Yale University and Federal policies and guidelines. Water was provided ad libitum and full monkey chow biscuits, fruits, and vegetables were provided each day. The animals were also provided with environmental enrichment that frequently consisted of preferred fruits, vegetables, and treats or juice.

\section{PET Occupancy Study}

The relationship between plasma concentration and GlyT1 transporter occupancy of Org 25935 (cis- $\mathrm{N}$-methyl- $\mathrm{N}$-(6methoxy-1-phenyl-1,2,3,4-tetrahydronaphthalen-2-ylmethyl) aminomethylcarboxylic acid hydrochloride; synthesized by GlaxoSmithKline, Kettering, UK) was investigated with PET in two rhesus monkeys (6 and $9 \mathrm{~kg}$ ) following single intravenous administrations. Occupancy was estimated from dynamic PET data acquired following administration of the GlyT-1 selective radioligand [11C]GSK931145. [11C]GSK931145 scans were performed at baseline and following administration of Org 25935 on the same day, with injections separated by $4 \mathrm{~h}$. Two different animals were studied, each receiving a single dose of Org 25935 $(0.1$ and $0.5 \mathrm{mg} / \mathrm{kg})$. Org 25935 was administered intravenously over $1 \mathrm{~h}$, beginning $85 \mathrm{~min}$ before the second tracer administration. Plasma samples were collected at regular intervals to estimate the plasma Org 25935 concentration.

The tracer $\left[{ }^{11} \mathrm{C}\right]$ GSK 931145 was synthesized with specific activity at end-of-synthesis of $5.8 \pm 1.1 \mathrm{mCi} / \mathrm{nmol}$ (Passchier et al, 2010). $\left[{ }^{11} \mathrm{C}\right] \mathrm{GSK} 931145$ was administered as a slow bolus over $1 \mathrm{~min}$ in quantities of $4.5 \pm 0.3 \mathrm{mCi}$ and $0.7 \pm 0.1 \mu \mathrm{g}$. PET emission data were acquired on a Focus220 animal scanner for $2 \mathrm{~h}$ and reconstructed into 33 frames with the filtered back projection algorithm. A metabolitecorrected, arterial plasma input function was estimated from sequential arterial samples processed to measure total radioactivity in plasma and the percentage of parent tracer by HPLC. Regional time-activity curves (TAC) were generated from regions of interest defined on an MRI template following registration of the template to each animal's individual brain MRI and registration of the PET images to each animal's MRI. Regional TAC were fitted to a two-tissue compartmental model to derive regional estimates of the total volume of distribution ( $V_{\mathrm{T}}$-equivalent to the tissue to plasma concentration ratio at equilibrium) (Gunn et al, 2011; Innis et al, 2007). Each $V_{\mathrm{T}}$ value was corrected for the free fraction of tracer in plasma, which was measured by ultrafiltration and ranged from 2 to $4 \%$. As GlyT-1 is expressed in all brain regions, the nondisplaceable distribution volume $\left(V_{\mathrm{ND}}\right)$ cannot be estimated by direct measurement of a reference region. Therefore, $V_{\mathrm{ND}}$ and GlyT-1 occupancies were computed using the occupancy plot (Cunningham et al, 2010) under the routine assumption that occupancy and $V_{\mathrm{ND}}$ are uniform across all brain regions. The plasma concentration of Org 25925 producing a $50 \%$ occupancy of the GlyT-1 $\left(\mathrm{IC}_{50}\right)$ was derived from these results. The estimated $\mathrm{IC}_{50}$ was used together with the plasma concentration profile measured following intramuscular (i.m.) administration of Org 25925 in order to determine the i.m. doses of Org 25925 used in the behavioral study. 


\section{Pharmacokinetic Study After i.m. Administration}

A pharmacokinetic study was conducted on two rhesus macaques to fully characterize the i.m. pharmacokinetic profile of Org 25935, select the doses for cognitive testing, and estimate the appropriate time of cognitive testing in relation to dosing.

\section{Primate Cognitive Neuropharmacology}

Seven monkeys were trained on the spatial delayed response task, as previously described (for a detailed description, see Roberts et al, 2010a). Briefly, monkeys were presented with spatially displaced wells and watched while the investigator baited one well with a highly palatable preferred food reward. Next, the wells were covered with identical plaques and an opaque screen was lowered for a variable delay. Once the screen was raised, the monkey was allowed to respond and was rewarded if it chose the baited well. Animals were trained to a stable baseline level of performance (65-75\% correct), so that both improvement and deficits could be detected. This stable baseline was achieved by either increasing the variable delay and/or increasing the number of spatially displaced wells. During the baseline period, animals were also acclimatized to both the chair and loose leg restraint for obtaining pk samples during both studies. Once baseline was established and acclimatization was completed, animals were tested in the assigned drug conditions, first for the single ascending dose study and second for the ketamine challenge study. Six animals completed both studies and one animal completed only the single ascending dose study.

On test days, Org 25935 or vehicle was administered i.m. 75 min before administration of either ketamine (median dose $1.0 \mathrm{mg} / \mathrm{kg}$ ) or placebo (sterile saline), which was administered $15 \mathrm{~min}$ before cognitive testing. Home cage behavioural observations were made for $5 \mathrm{~min}$ following the second injection using a computerized program, SimTrack (Castner et al, 2010). This program tracks gross abnormal behaviors such as hallucinatory-like behavior (unusual tracking, hypervigilance, excessive checking, staring into space, and manipulation of thin air). For the six animals that completed both studies, a single plasma sample was taken immediately after cognitive testing (ie, $\sim 15-25 \mathrm{~min}$ after the start of cognitive testing).

Treatment conditions were assigned according to an initial single ascending dose design (Phase I) followed by a yoked Latin-square design with vehicle/Org 25935 vs ketamine (Phase II). The doses for Phase II were selected on the basis of the behavioural tolerability observed in Phase 1, expected efficacious occupancy, and effects on cognitive performance.

A minimum 1 week washout between Org 25935 or ketamine conditions was required to ensure that the animals were performing within their baseline performance level before their next treatment (ie, 2-3 test sessions).

\section{Analysis}

Spatial delayed response data and behavioural observation data were analysed by one-way analysis of variance (ANOVA) with Scheffe post-hoc comparisons. Two-way
ANOVA was performed for the data obtained across the different delays of the spatial delayed response task to determine whether there were main effects of delay and treatment condition. A linear regression analysis was used to examine the relationship between Org 25935 concentrations and spatial delayed response performance for both the single ascending dose regimen and the ketamine challenge study.

\section{RESULTS}

\section{PET Occupancy Study}

Figure 1 displays images of the uptake of $\left[{ }^{11} \mathrm{C}\right] \mathrm{GSK} 931145$ at baseline and following the administration of $0.5 \mathrm{mg} / \mathrm{kg}$ of Org 25935. As previously described (Gunn et al, 2011), $\left[{ }^{11} \mathrm{C}\right]$ GSK931145 uptake was the highest in regions known to be rich in GlyT-1 (midbrain > thalamus > cerebellum > cortex). The uptake of the tracer was substantially reduced by preadministration of Org 25935 (Figure 2). GlyT-1 occupancy was calculated as $81 \%$ following the $0.5 \mathrm{mg} / \mathrm{kg}$ dose and $31 \%$ following the $0.1 \mathrm{mg} / \mathrm{kg}$ dose.

The $0.5 \mathrm{mg} / \mathrm{kg}$ i.v. dose of Org 25935 yielded a plasma concentration of $597 \mathrm{ng} / \mathrm{ml}$ at the start of the scan and an average plasma concentration of $257 \mathrm{ng} / \mathrm{ml}$ over the duration of the scan. The $0.1 \mathrm{mg} / \mathrm{kg}$ i.v. Org 25935 yielded a plasma concentration of $124 \mathrm{ng} / \mathrm{ml}$ at the start of scan and an average plasma concentration of $60 \mathrm{ng} / \mathrm{ml}$ over the duration of the scan. The average predicted Org 25935 i.v. $\mathrm{ED}_{50}$ was $0.17 \mathrm{mg} / \mathrm{kg}$, with an $\mathrm{IC}_{50}$ of $97 \mathrm{ng} / \mathrm{ml}$.

\section{Pharmacokinetic Study After i.m. Administration}

Examination of the pharmacokinetic profile of Org 25935 following i.m. administration revealed a $T_{\max }$ equal to $1 \mathrm{~h}$. A combination of the i.m. pharmacokinetic data with the results of the PET studies yielded an i.m. $\mathrm{ED}_{50}$ of $0.43 \mathrm{mg} / \mathrm{kg}$. On the basis of these data, the following four doses were selected for the behavioural study: $0.15 \mathrm{mg} / \mathrm{kg}$ (estimated GlyT-1 occupancy $\sim 25 \%), \quad 0.3 \mathrm{mg} / \mathrm{kg}$ (estimated GlyT-1 occupancy $\sim 40 \%), 0.6 \mathrm{mg} / \mathrm{kg}$ (estimated GlyT-1 occupancy $\sim 60 \%$ ), and $1.0 \mathrm{mg} / \mathrm{kg}$ (estimated GlyT-1 occupancy $\sim 70 \%$ ).

\section{Baseline Cognitive Studies}

Pretreatment with Org 25935 produced impaired spatial working memory performance across the group at the highest dose tested of $1.0 \mathrm{mg} / \mathrm{kg}$ and was without effect on performance at all other doses (Figure 3). A one-way ANOVA for delayed response performance revealed a significant effect of $\operatorname{Org} 25935(\mathrm{~F}(4,29)=6.83 ; P=0.001)$. Post-hoc analysis revealed that Org $25935(1.0 \mathrm{mg} / \mathrm{kg})$ impaired cognitive performance as compared with vehicle/ placebo (Scheffe post-hoc comparison; $P=0.003$ ).

Further analysis of the pattern of errors across conditions in the single ascending dose study demonstrated that the $1.0 \mathrm{mg} / \mathrm{kg}$ dose of Org 25935 showed a trend for increasing the number of errors made by animals at longer delays as compared with shorter delays (Figure 3). Two-way ANOVA across vehicle/placebo, $0.3 \mathrm{mg} / \mathrm{kg}$ Org 25935/placebo, and $1.0 \mathrm{mg} / \mathrm{kg}$ Org 25935/placebo showed that there were main effects of condition $(\mathrm{F}(2,10)=11.774 ; P=0.002)$ and delay $(\mathrm{F}(4,20)=5.10 ; P=0.005)$ but no significant interaction 


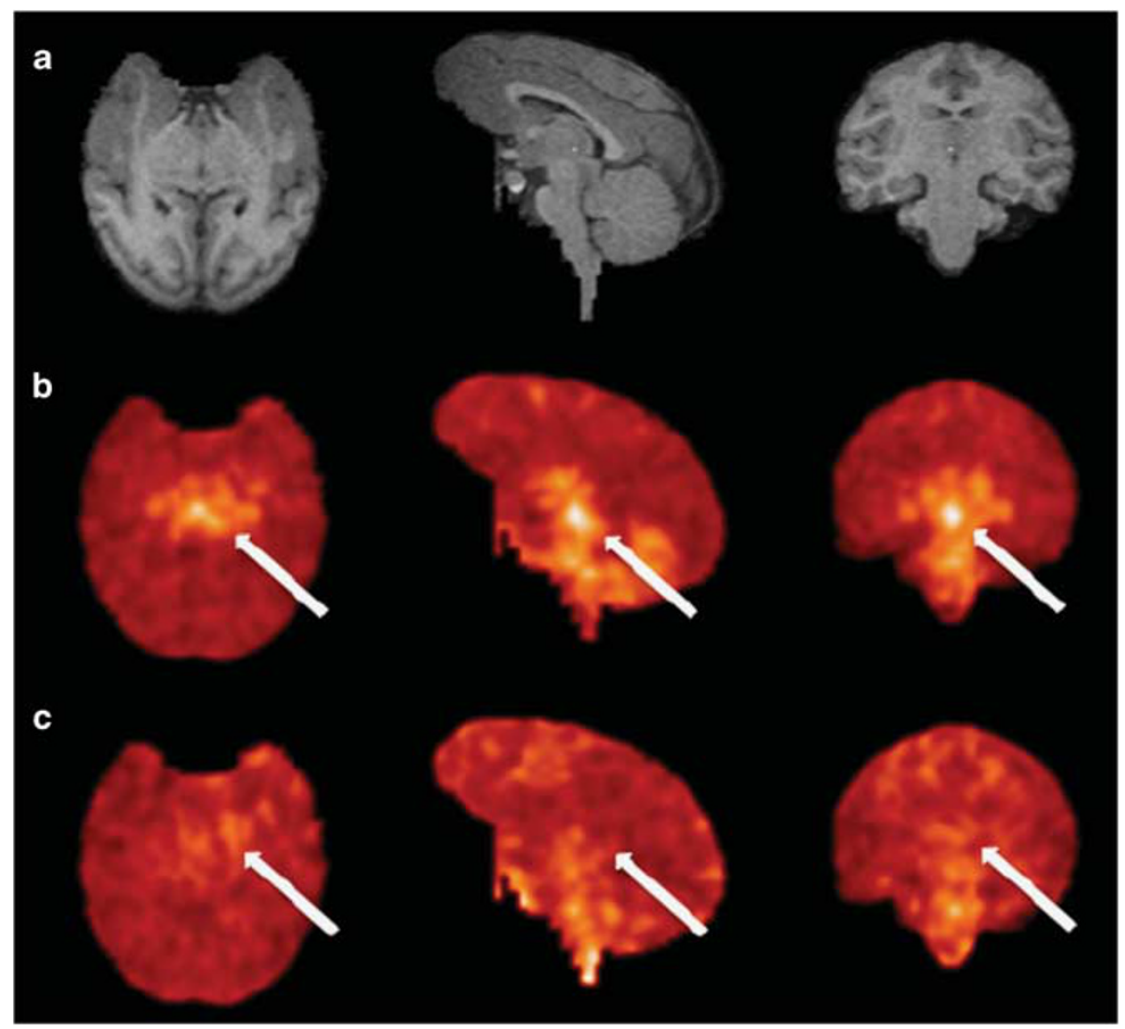

Figure I (a) MR slices from rhesus monkey in transverse, sagittal, and coronal orientations. (b) Registered PET images in the control study following bolus injection of [ I I C]GSK93 I I45. (c) Matching images following administration of 0.5 mg/kg Org 25935. PET images are on a common SUV scale (corrected for injection dose and body weight). Blockade of specific binding is visible by increased uniformity in the blocking scans. The activity concentration at the level of the midbrain (arrows) is not detected after Org 25935 administration.

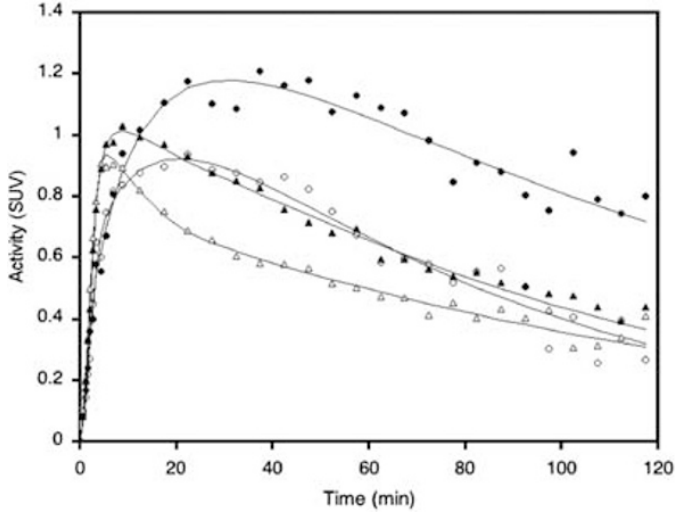

Figure 2 Example of time-activity curves and fits to the $2 T$ model from two regions from the study shown above (ie, in image figure). Circles are brainstem and triangles are occipital cortex values. Filled symbols are from the baseline scan and open symbols are from the scan performed following blockade with Org 25935.

$(\mathrm{F}(8,40)=0.572 ; P=0.79)$. A significant negative slope of cognitive performance against plasma exposure was revealed by linear regression (Figure 4).

No significant effects of Org 25935 were noted on either the expression of hallucinatory-like behaviours (virtually absent under placebo conditions) or the percentage time spent by monkeys engaged in other gross motor behaviours $(\mathrm{F}(4,29)=0.090 ; P=0.98)$.

\section{Ketamine Cognitive Studies}

Acute ketamine (median dose $1.0 \mathrm{mg} / \mathrm{kg}$ ) produced profound impairments in spatial delayed response performances (Figure 5). The ability of ketamine to impair working memory was reversed by pretreatment with Org 25935. One-way ANOVA across ketamine conditions revealed a significant main effect of pretreatment $(\mathrm{F}(3,20)=5.715 ; P=0.005$; Figure 5).

Whereas the dose of $0.5 \mathrm{mg} / \mathrm{kg}$ had a prominent protective effect against ketamine (Scheffe post-hoc comparison, $P=0.008$ ), the higher dose of $1.0 \mathrm{mg} / \mathrm{kg}$ was only marginal for this protection $(P=0.05)$. In contrast, the lowest dose of $0.15 \mathrm{mg} / \mathrm{kg}$ tested was ineffective against ketamine's ability to impair cognition $(P=0.25)$. In order to better understand this protective effect of the GlyT1 inhibitor, we examined the pattern of errors under three conditions: vehicle/placebo, vehicle/ketamine, and $0.5 \mathrm{mg} / \mathrm{kg}$ Org 25935/ketamine. Two-way ANOVA reported the main effects of condition $(\mathrm{F}(2,10)=16.2 ; P=0.001)$ and delay $(\mathrm{F}(4,20)=5.61 ; P=0.003)$, but no interaction between them $(\mathrm{F}(8,40)=0.76 ; \quad P=0.63)$. Ketamine induced an increase in errors across all delays, and pretreatment with $0.5 \mathrm{mg} / \mathrm{kg}$ Org 25935 reduced these errors towards that of the vehicle/placebo condition (Figure 5b).

After plasma concentration measures of Org 25935 in the presence of ketamine were analysed, a significant positive slope of performance against exposure was revealed by linear regression. This correlation was highly significant 
a

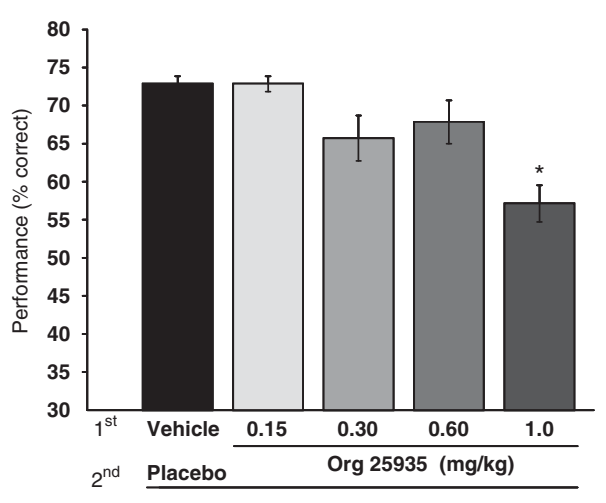

b

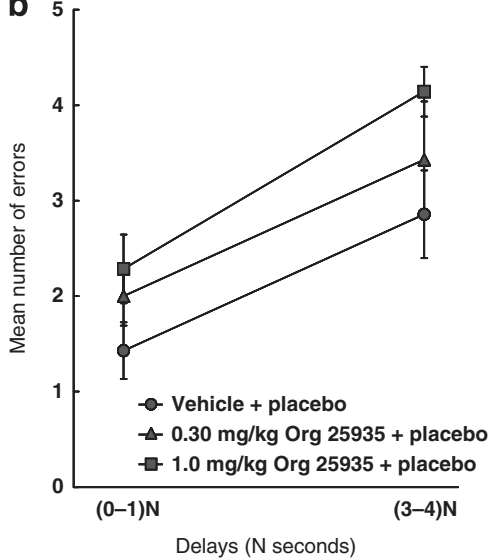

Figure 3 Effects of the GlyTI inhibitor under control conditions. (a) Effect on cognitive performance of the four doses tested in comparison with vehicle. The highest dose of $1.0 \mathrm{mg} / \mathrm{kg}$ impaired working memory as compared with the vehicle/placebo (* indicates significant difference from vehicle/placebo $P=0.00$ I by Scheffe post-hoc comparison). (b) The mean number of errors at short and long delays $(N=0-1$ and $N=3-4)$ for spatial delayed response performance for the single ascending dose study of Org 25935.

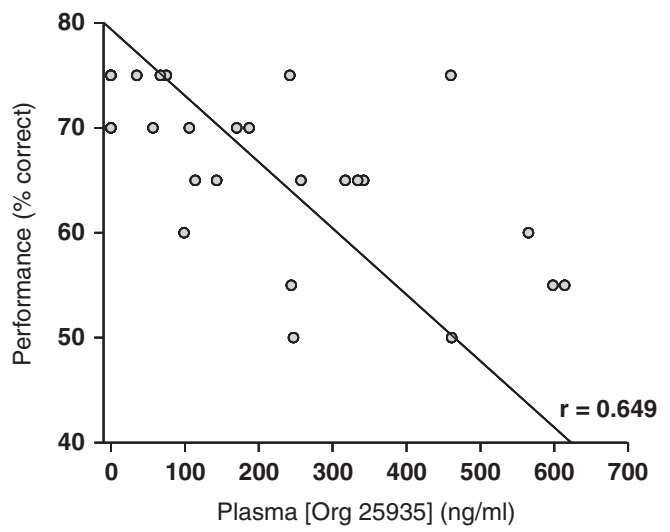

Figure 4 Relationship between working memory performance and plasma exposure to Org 25935 under controlled condition. A linear negative correlation was found between performance and plasma Org 25935 concentration.

$(\mathrm{F}(1,22)=11.7 ; P=0.002 ; r=0.59$; Figure 6$)$. Of note, the relationship between cognitive performance and plasma exposure of Org 25935 could equally be fit to a quadratic function $(r=0.74$, Figure 6).

Ketamine induced a robust emergence of abnormal, hallucinatory-like behaviours but did not produce other significant alterations in gross motor activities. Pretreatment with Org 25935 did not attenuate the induction of these abnormal behaviours $(F(3,20)=0.65 ; P=0.59)$. It also did not influence the mean percentage time spent engaged in gross motor behaviours $(\mathrm{F}(3,20)=0.40 ; P=0.75)$.

\section{DISCUSSION}

This study examined the effects of a GlyT-1 inhibitor on working memory performance in rhesus monkeys and the ability of this mechanism to restore these performances when impaired by the administration of ketamine. In addition, PET occupancy studies were carried out to estimate the degree of GlyT-1 inhibition at which the effects are observed. The data showed that (a) the GlyT-1 inhibitor did not improve working memory performance in healthy animals and in fact worsened these performances at high levels of GlyT-1 occupancy ( $>75 \%$ occupancy); (b) the GlyT-1 inhibitor almost completely restored working memory deficits induced by a dose of ketamine that reduced performance by half, and did so optimally at a GlyT-1 occupancy in the $50-75 \%$ range. To the extent that the acute administration of ketamine in rhesus monkeys in this dose range is an appropriate preclinical model of the cognitive impairment observed in schizophrenia, these data suggest that clinical trials of GlyT-1 inhibitors aimed at improving cognition in patients with schizophrenia should include at least one dose inducing 50-70\% GlyT-1 occupancy. Lower occupancies might not translate into adequate rescue of NMDA transmission, whereas higher occupancies might be associated with less than optimal, if not negative, effects on cognition.

The behavioural data presented here are in line with the general pharmacology of this class of compound in rodents, which have shown more robust effect at restoring behavioural impairment owing to the administration of NMDA receptor antagonists than at improving cognitive performances in untreated animals (reviewed in Marek et al, 2010). GlyT-1 inhibitors also reverse the pattern of metabolic activation induced by PCP in rats measured with fMRI (Gozzi et al, 2008).

The result of this study is comparable to the study previously reported in rhesus using the same paradigm (ketamine-induced deficit in spatial working memory) and a different GlyT-1 inhibitor, PF-3463275 (Roberts et al, 2010b). In both studies, the deficit induced by ketamine was independent of the delay, suggesting a global effect on encoding and performance rather than a selective retention effect. Both GlyT-1 inhibitors showed a restoration of ketamine-induced cognitive deficit in the dose range studied. One noticeable difference is that, while using PF-3463275 at a dose range of $0.01-0.17 \mathrm{mg} / \mathrm{kg}$, we did not observe significant effects on cognitive performance in the 

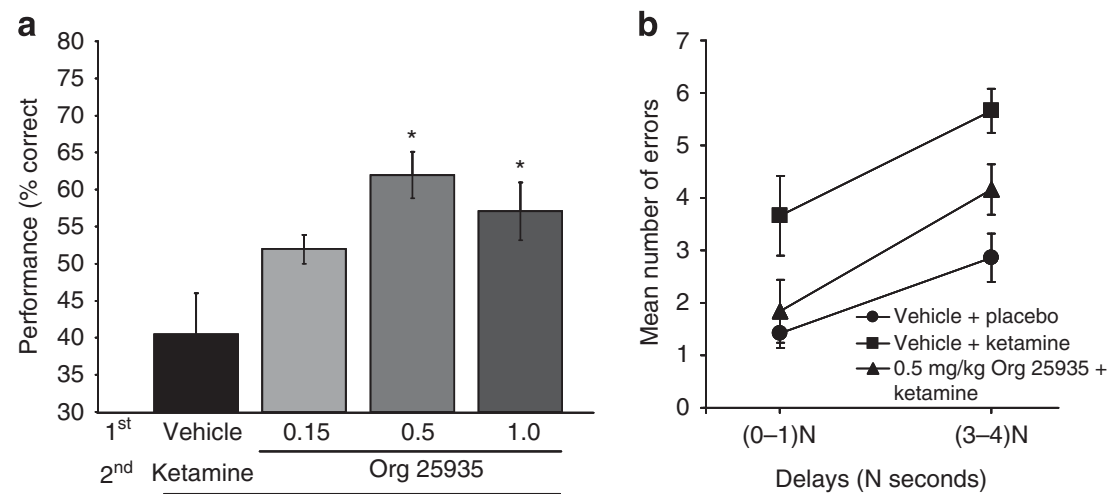

Figure 5 Effects of the GlyTI inhibitor under ketamine conditions: (a) Ketamine profoundly impaired spatial working memory and pretreatment with Org $25935(0.5$ and $1.0 \mathrm{mg} / \mathrm{kg}$ ) provided significant protection against this deficit (* indicates significant difference between vehicle and ketamine: $0.5 \mathrm{mg} / \mathrm{kg}$ : $P=0.008$ and $1.0 \mathrm{mg} / \mathrm{kg}: P 0.050$ by Scheffe post-hoc comparison, respectively). (b) Mean number of errors at short and long delays ( $\mathrm{N}=1-10 \mathrm{~s}$ dependent upon task difficulty) for spatial delayed response performance for the ketamine challenge study with Org 25935.

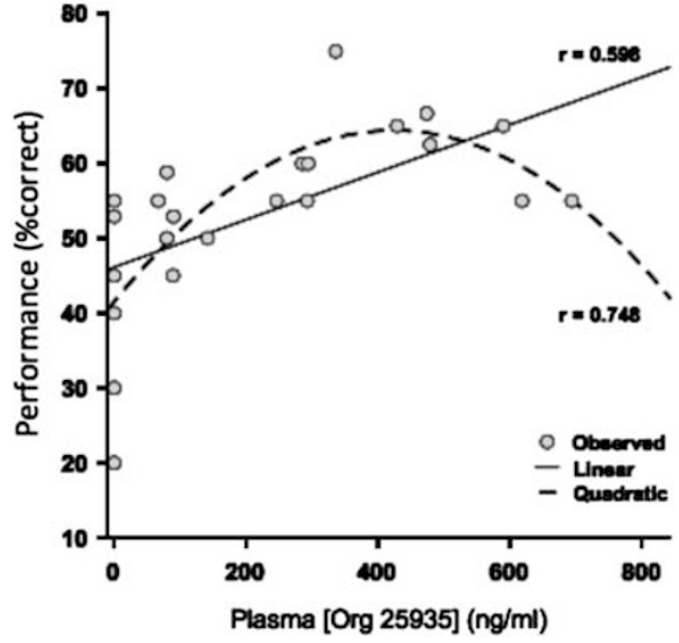

Figure 6 Relationship between working memory performance and plasma exposure to Org 25935 under controlled condition. A quadratic model provided a better fit than a linear model for the relationship between cognitive performance and plasma Org 25935 concentration under ketamine conditions.

control state, but we observed a significant decrement with Org 25935 at the highest dose. As GlyT-1 occupancy was not measured in the PF-3463275 study (Roberts et al, 2010b), it is possible that the highest dose of PF-3463275 did not reach the level of GlyT-1 occupancy associated with the highest dose of Org 25935 used here.

Reversal of some ketamine-induced effects by Org 25935 has been recently reported in healthy volunteers (D'Souza et al, 2011). At an oral dose of $16 \mathrm{mg}$, Org 25935 reduced the ketamine-induced increase in the total scores of positive and negative symptoms (PANSS), with a trend level reduction in the positive symptom subscale and no effect on the negative symptom subscale. On the other hand, this dose had no effect on ketamine-induced cognitive deficit. It should also be noted that, in the absence of ketamine, the $16 \mathrm{mg}$ dose of Org 25935 induced significant sedation and impaired working memory in healthy humans, just like the highest dose of Org 25935 used in this study. Thus, although the dose-GlyT occupancy relationship of Org 25935 in humans has not been reported, the comparison between the two studies suggests that high occupancy was achieved in humans at the $16 \mathrm{mg}$ dose (impairment of cognition at baseline and lack of effect on ketamine-impaired cognition). This suggestion is in line with data reported in a recent study on the efficacy of Org 25935 as augmentation to cognitive therapy in panic disorder (Nations et al, 2012). The tested doses were 4 and $12 \mathrm{mg}$. These doses were shown to significantly engage the GlyT-1 in healthy volunteers, as demonstrated by the induction of a 1.5- and 4.5-fold increase in glycine concentration in the cerebrospinal fluid, respectively. The authors also stated that doses higher than $12 \mathrm{mg}$ were associated with significant adverse effects (data on file at Merck).

Assuming that the attenuation of the PANSS score increase induced by ketamine is predictive of an antipsychotic effect, it might be speculated that the occupancy of GlyT-1 associated with antipsychotic or sedative effects might be higher than that associated with optimal improvement of cognitive function.

The notion that an inverted U-shaped curve characterizes the pro-cognitive effects of GlyT-1 inhibitors in NMDAimpaired animals is also consistent with the results of a phase 2 study recently reported in stable patients with schizophrenia (Umbricht et al, 2014). Stable patients maintained on second-generation antipsychotic drugs were randomized to treatment with placebo, or with the GlyT-1 inhibitor bitopertin (RG1678) at doses of 10, 30 or $60 \mathrm{mg} /$ day. A significantly larger reduction in negative symptoms and improvement in social function were observed after 8 weeks in the 10 and $30 \mathrm{mg} /$ day dose groups when compared with placebo-treated patients, but not in the $60 \mathrm{mg} /$ day group. On the basis of plasma levels observed in this study and as per bitopertin PET occupancy studies (L Santarelli, Roche, personal communication and MartinFacklam et al, 2013), the GlyT-1 average occupancy achieved in the clinical study at doses of 10,30 , and $60 \mathrm{mg} /$ day is estimated at $40 \pm 10,61 \pm 7$ and $73 \pm 6 \%$, respectively. Thus, despite the small number of PET scans obtained in this primate study and recognizing that improvement in negative symptoms observed in the clinical study and 
improvement in ketamine-induced working memory deficits reported in rhesus are not equivalent, both sets of data converge in pointing towards a $40-70 \%$ occupancy range as optimal for remediation in stable patients with schizophrenia.

Several mechanisms might account for the detrimental effects or loss of efficacy at the higher level of GlyT-1 occupancy observed here. Under some experimental conditions, high levels of glycine have been associated with internalization of NMDA receptors and detrimental effects on cognition (Martina et al, 2004; Singer et al, 2009). High glycine levels have also been associated with engagement of strychnine-sensitive inhibitory glycine receptors (Zhang et al, 2008), which might cause drowsiness and sedation. Finally, it has been proposed that, in the cortex and hippocampus, NMDA receptors expressed on gabaergic interneurons are more vulnerable to the effect of NMDA receptor agonists than those expressed on pyramidal cells (Homayoun and Moghaddam, 2007; Lisman et al, 2008). Moderate increase in glycine levels might restore NMDA receptor function on gabaergic neurons, whereas excessive levels might engage unimpaired NMDA receptors on pyramidal cells.

The lack of positive effects on spatial working memory of the GlyT-1 inhibitors at any level of occupancy reported here and in Roberts et al (2010b) in healthy rhesus suggests that, in the absence of NMDA receptor deficit, GlyT-1 inhibitors might only worsen cognitive performances. As the existence and severity of an NMDA receptor deficit might vary in patients with schizophrenia, this result predicts a large heterogeneity in the cognitive effect of these agents in patients with schizophrenia. Biomarkers predictive of the severity of NMDA receptor deficits would thus be invaluable for the development of these agents.

In conclusion, the data reported in this study suggest that GlyT-1 inhibitors might not provide beneficial effects on working memory performance in healthy primates, but are able to restore working memory functions when impaired by a relative NMDA receptor blockade. In this model, GlyT-1 occupancy higher than $75 \%$ was associated with an adverse effect on working memory performance in healthy rhesus and with a blunting of the restorative effect under NMDA receptor blockade conditions. Both sets of data suggest that clinical trials aimed at cognitive and social remediation in stable patients with schizophrenia should include at least one dose targeting a $40-70 \%$ GlyT-1 occupancy range.

\section{ACKNOWLEDGEMENTS}

We thank Daniel Holden, Heather Findlay, Amanda Abbott, and the staff of the Yale PET Centre for excellent technical support. This study was funded by GlaxoSmithKline.

\section{FUNDING AND DISCLOSURE}

NVM, RK, HH, EAR, RNG and ML were GSK employees at the time these studies were conducted and are GSK shareholders. NVM is a full-time employee of Takeda. WGV and CSA are recipients of Pfizer funding. HY and CRE are recipients of funding from Pfizer, Abbot, BMS, and Ely Lilly. ML was a consultant for Roche, Amgen, and Pfizer and is now employee of UCB Pharma.

\section{REFERENCES}

Alberati D, Moreau JL, Lengyel J, Hauser N, Mory R, Borroni E et al (2011). Glycine reuptake inhibitor RG1678: a pharmacologic characterization of an investigational agent for the treatment of schizophrenia. Neuropharmacology 62: 1152-1161.

Bergeron R, Meyer TM, Coyle JT, Greene RW (1998). Modulation of N-methyl-D-aspartate receptor function by glycine transport. Proc Natl Acad Sci USA 95: 15730-15734.

Borowsky B, Mezey E, Hoffman BJ (1993). Two glycine transporter variants with distinct localization in the CNS and peripheral tissues are encoded by a common gene. Neuron 10: 851-863.

Borroni E, Zhou Y, Ostrowitzki S, Alberati D, Kumar A, Hainzl D et al (2013). Pre-clinical characterization of [(11)C]R05013853 as a novel radiotracer for imaging of the glycine transporter type 1 by positron emission tomography. Neuroimage 75: 291-300.

Boulay D, Bergis O, Avenet P, Griebel G (2010). The glycine transporter-1 inhibitor SSR103800 displays a selective and specific antipsychotic-like profile in normal and transgenic mice. Neuropsychopharmacology 35: 416-427.

Castner SA, Arriza JL, Roberts JC, Mrzljak L, Christian EP, Williams GV (2010). Reversal of ketamine-induced working memory impairments by the GABAAalpha2/3 agonist TPA023. Biol Psychiatry 67: 998-1001.

Chen GM, Weston JK (1960). The analgesic and anesthetic effect of 1-(1-phenylcyclohexyl) piperidine $\mathrm{HCl}$ on the monkey. Anesth Analg 39: 132-137.

Coyle JT (2004). The GABA-glutamate connection in schizophrenia: which is the proximate cause? Biochem Pharmacol 68: 1507-1514.

Cunningham VJ, Rabiner EA, Slifstein M, Laruelle M, Gunn RN (2010). Measuring drug occupancy in the absence of a reference region: the Lassen plot re-visited. J Cereb Blood Flow Metab 30: $46-50$.

D'Souza DC, Singh N, Elander J, Carbuto M, Pittman B, Udo de Haes J et al (2011). Glycine transporter inhibitor attenuates the psychotomimetic effects of ketamine in healthy males: preliminary evidence. Neuropsychopharmacology 37: 1036-1046.

Dingledine R, Kleckner NW, McBain CJ (1990). The glycine coagonist site of the NMDA receptor. Adv Exp Med Biol 268: 17-26.

Gozzi A, Herdon H, Schwarz A, Bertani S, Crestan V, Turrini G et al (2008). Pharmacological stimulation of NMDA receptors via co-agonist site suppresses fMRI response to phencyclidine in the rat. Psychopharmacology (Berl) 201: 273-284.

Gunn RN, Murthy V, Catafau AM, Searle G, Bullich S, Slifstein M et al (2011). Translational characterization of [(11) C]GSK931145, a PET ligand for the glycine transporter type 1. Synapse 65: 1319-1332.

Hamill TG, Eng W, Jennings A, Lewis R, Thomas S, Wood S et al (2011). The synthesis and preclinical evaluation in rhesus monkey of [(1)F]MK-6577 and [(1)(1)C]CMPyPB glycine transporter 1 positron emission tomography radiotracers. Synapse 65 : 261-270.

Hashimoto K (2011). Glycine transporter-1: a new potential therapeutic target for schizophrenia. Curr Pharm Des 17: 112-120.

Homayoun H, Moghaddam B (2007). Fine-tuning of awake prefrontal cortex neurons by clozapine: comparison with haloperidol and N-desmethylclozapine. Biol Psychiatry 61: 679-687.

Hui C, Wardwell B, Tsai GE (2009). Novel therapies for schizophrenia: understanding the glutamatergic synapse and potential targets for altering N-methyl-D-aspartate neurotransmission. Recent Pat CNS Drug Discov 4: 220-238.

Innis RB, Cunningham VJ, Delforge J, Fujita M, Gjedde A, Gunn RN et al (2007). Consensus nomenclature for in vivo imaging of reversibly binding radioligands. J Cereb Blood Flow Metab 27: 1533-1539. 
Javitt DC (2008). Glycine transport inhibitors and the treatment of schizophrenia. Biol Psychiatry 63: 6-8.

Javitt DC (2009). Glycine transport inhibitors for the treatment of schizophrenia: symptom and disease modification. Curr Opin Drug Discov Devel 12: 468-478.

Javitt DC, Zukin SR (1991). Recent advances in the phencyclidine model of schizophrenia. Am J Psychiatry 148: 1301-1308.

Kantrowitz JT, Javitt DC (2010). N-methyl-d-aspartate (NMDA) receptor dysfunction or dysregulation: the final common pathway on the road to schizophrenia? Brain Res Bull 83: 108-121.

Krystal JH, Karper LP, Seibyl JP, Freeman GK, Delaney R, Bremner JD et al (1994). Subanesthetic effects of the noncompetitive NMDA antagonist, ketamine, in humans. Psychotomimetic, perceptual, cognitive, and neuroendocrine responses. Arch Gen Psychiatry 51: 199-214.

Lechner SM (2006). Glutamate-based therapeutic approaches: inhibitors of glycine transport. Curr Opin Pharmacol. 6: 75-81.

Lisman JE, Coyle JT, Green RW, Javitt DC, Benes FM, Heckers S et al (2008). Circuit-based framework for understanding neurotransmitter and risk gene interactions in schizophrenia. Trends Neurosci 31: 234-242.

Liu QR, Lopez-Corcuera B, Mandiyan S, Nelson H, Nelson N (1993). Cloning and expression of a spinal cord- and brainspecific glycine transporter with novel structural features. J Biol Chem 268: 22802-22808.

Luby ED, Gottlieb JS, Cohen BD, Rosenbaum G, Domino EF (1962). Model psychoses and schizophrenia. Am J Psychiatry 119: 61-67.

Marek GJ, Behl B, Bespalov AY, Gross G, Lee Y, Schoemaker H (2010). Glutamatergic (N-methyl-D-aspartate receptor) hypofrontality in schizophrenia: too little juice or a miswired brain? Mol Pharmacol 77: 317-326.

Martin-Facklam M, Pizzagalli F, Zhou Y, Ostrowitzki S, Raymont V, Brašić JR et al (2013). Glycine transporter type 1 occupancy by bitopertin: a positron emission tomography study in healthy volunteers. Neuropsychopharmacology 38: 504-512.

Martina M, Gorfinkel Y, Halman S, Lowe JA, Periyalwar P, Schmidt CJ et al (2004). Glycine transporter type 1 blockade changes NMDA receptor-mediated responses and LTP in hippocampal CA1 pyramidal cells by altering extracellular glycine levels. J Physiol 557: 489-500.

Moghaddam B, Javitt D (2012). From revolution to evolution: the glutamate hypothesis of schizophrenia and its implication for treatment. Neuropsychopharmacology 37: 4-15.

Nations KR, Smits JA, Tolin DF, Rothbaum BO, Hofmann SG, Tart CD et al (2012). Evaluation of the glycine transporter inhibitor Org 25935 as augmentation to cognitive-behavioral therapy for panic disorder: a multicenter, randomized, doubleblind, placebo-controlled trial. J Clin Psychiatry 73: 647-653.

Passchier J, Gentile G, Porter R, Herdon H, Salinas C, Jakobsen S et al (2010). Identification and evaluation of [11C]GSK931145 as a novel ligand for imaging the type 1 glycine transporter with positron emission tomography. Synapse 64: 542-549.
Roberts BM, Seymour PA, Schmidt CJ, Williams GV, Castner SA (2010a). Amelioration of ketamine-induced working memory deficits by dopamine D1 receptor agonists. Psychopharmacology (Berl) 210: 407-418.

Roberts BM, Shaffer CL, Seymour PA, Schmidt CJ, Williams GV, Castner SA (2010b). Glycine transporter inhibition reverses ketamine-induced working memory deficits. Neuroreport 21: 390-394.

Sanabria-Bohorquez SM, Joshi AD, Holahan M, Daneker L, Riffel K, Williams M et al (2011). Quantification of the glycine transporter 1 in rhesus monkey brain using [(18)F]MK-6577 and a model-based input function. Neuroimage 59: 2589-2599.

Singer P, Yee BK, Feldon J, Iwasato T, Itohara S, Grampp T et al (2009). Altered mnemonic functions and resistance to N-METHYLd-Aspartate receptor antagonism by forebrain conditional knockout of glycine transporter 1. Neuroscience 161: 635-654.

Singh SP, Singh V (2011). Meta-analysis of the efficacy of adjunctive NMDA receptor modulators in chronic schizophrenia. CNS Drugs 25: 859-885.

Smith KE, Borden LA, Hartig PR, Branchek T, Weinshank RL (1992). Cloning and expression of a glycine transporter reveal colocalization with NMDA receptors. Neuron 8: 927-935.

Thomson AM (1990). Glycine is a coagonist at the NMDA receptor/channel complex. Prog Neurobiol 35: 53-74.

Tsai GE, Lin PY (2010). Strategies to enhance N-methyl-D-aspartate receptor-mediated neurotransmission in schizophrenia, a critical review and meta-analysis. Curr Pharm Des 16: 522-537.

Umbricht D, Alberati D, Martin-Facklam M, Borroni E, Youssef EA, Ostland $M$ et al (2014). Effect of bitopertin, a glycine reuptake inhibitor, on negative symptoms of schizophrenia: a randomized, double-blind, proof-of-concept study. JAMA Psychiatry 71: 637-646.

Wallace TL, Ballard TM, Pouzet B, Riedel WJ, Wettstein JG (2011). Drug targets for cognitive enhancement in neuropsychiatric disorders. Pharmacol Biochem Behav 99: 130-145.

Wolkenberg SE, Sur C (2010). Recent progress in the discovery of non-sarcosine based GlyT1 inhibitors. Curr Top Med Chem 10: $170-186$.

Wong DF, Ostrowitzki S, Zhou Y, Raymont V, Hofmann C, Borroni E et al (2011). Characterization of [(11)C]RO5013853, a novel PET tracer for the glycine transporter Type 1 (Glyt1) in humans. Neuroimage 75: 282-290.

Yang SY, Hong CJ, Huang YH, Tsai SJ (2010). The effects of glycine transporter I inhibitor, N-methylglycine (sarcosine), on ketamine-induced alterations in sensorimotor gating and regional brain c-Fos expression in rats. Neurosci Lett 469: $127-130$.

Zhang J, Wu J, Toyohara J, Fujita Y, Chen H, Hashimoto K (2011). Pharmacological characterization of [(3)H]CHIBA-3007 binding to glycine transporter 1 in the rat brain. PLoS One 6: e21322.

Zhang Z, Gong N, Wang W, Xu L, Xu TL (2008). Bell-shaped $\mathrm{D}$-serine actions on hippocampal long-term depression and spatial memory retrieval. Cereb Cortex 18: 2391-2401. 